\title{
COOPERACIÓN JUDICIAL INTERNACIONAL EN EL SISTEMA DE DERECHO INTERNACIONAL PRIVADO PERUANO
}

\author{
Marcela Arriola Espino*
}

\begin{abstract}
Resumen:
El Derecho Internacional privado se vincula con las diferentes disciplinas jurídicas; de ahí que dentro del marco del Derecho Procesal Internacional, uno de sus importantes temas lo sea la Cooperación Judicial Internacional también Ilamada Asistencia Judicial Internacional.

La práctica de actos procesales fuera del lugar del proceso con elemento extranjero es común y, ello es posible gracias a la voluntad de los Estados de que el principio de soberanía y de territorialidad del proceso no sea un impedimento para la actuación de diligencias fundamentales que permitan dilucidar una controversia. La práctica de notificaciones, actuación de pruebas, ejecución de medidas cautelares, e información del Derecho extranjero, utilizando el mecanismo del exhorto internacional o carta rogatoria, invocando tratados sobre la materia o el principio de reciprocidad, lo permite. Una breve visión al respecto, teniendo en cuenta el sistema de Derecho Internacional Privado peruano, se trata en este trabajo.
\end{abstract}

Palabras clave: Carta rogatoria - Cooperación Judicial Internacional Derecho Internacional Privado.

\begin{abstract}
A bstract:
The Private International Law is related to different legal disciplines; for that reason, one of their important subjects within the frame of the International Procedural Law is the International Judicial Cooperation, which is called international judicial attendance.

The practice of procedural acts outside the place of the process with foreign element is common, and that is possible thanks to the will of the States making the territoriality and sovereignty principle of the process not an impediment for the performance of fundamental diligences that allows to explain the controversy.

This work is a brief vision about the Peruvian Private International Law System.
\end{abstract}

Key words: Letters rogatory - International Judicial Cooperation International Private Law.

Sumario:

1. Introducción. 2. Concepto y fundamento. 3. Actos procesales que requieren de asistencia judicial internacional. Carta rogatoria. 4. Cooperación judicial internacional en el ordenamiento jurídico nacional. Régimen Convencional: Tratados Multilaterales, Tratados bilaterales. Régimen Común. 5. A manera de conclusión.

* Vocal Titular. PresidentadelaPrimera SalaCivil dela CorteSuperior deJusticiadelca- Perú. DocenteUniversitaria. 
Marcela Arriola Espino - Cooperación judicial internacional en el sistema de derecho internacional privado peruano

\section{INTRODUCCIÓN}

En la búsqueda del bien común, el Estado, dotado desu poder soberano, cumple determinados fines o funciones.

La tradicional teoría de separación de poderes desarrollada y expuesta por Locke $y$, especialmente por Montesquieu, planteada dentro del contexto político y jurídico dela época; fue evolucionando hasta entender queel poder del Estado es uno y que tiene órganos a través de los cuales cumple determinadas funciones. Como lo señala Loewenstein, "La separación de poderes no es sino la forma clásica de expresar la necesidad de distribuir y controlar respectivamenteel ejercicio del poder político. Lo quecorrientemente, aunque erróneamente, se suele designar como la separación de los poderes estatales, es en real idad la distribución de determinadas funciones estatales a diferentes órganos del Estado" ${ }^{\prime 1}$.

Es así, que la función jurisdiccional encomendada a los jueces o magistrados está destinadaa la administración dejusticia o a decir el Derecho a instancia de parteo de oficio, cuando procede, juzgando demanera irrevocabley ejecutando lo juzgado. Pero esa potestad de administrar justicia aún dentro del territorio de un Estado, tiene límites que establece la ley; de ahí que se hable de la competencia de un juez para conocer de determinados asuntos.

Como lo señala Couture, "la relación entre la jurisdicción y la competencia, es la relación que existe entre el todo y la parte. La jurisdicción es el todo; la competencia es la parte: un fragmento dela jurisdicción. La competencia es la potestad dejurisdicción para una partedel sector jurídico: aquel específicamente asignado al conocimiento de determinado órgano jurisdiccional. En todo aquello que no le ha sido atribuido, un juez, aunque sigue teniendo jurisdicción, es incompetente" 2 . Es por ello que, si en un proceso se deben realizar ciertas diligencias o actos procesales fuera del territorio en donde ejerce competencia el juez de la causa, debe solicitar colaboración -vía exhorto- al órgano jurisdiccional pertinente que, por lo general es de igual jerárquica, para que practique la notificación o actuación de prueba encomendada.

Ese ruego, ayuda o cooperación judicial que los jueces formulan a sus pares nacionales, también lo pueden hacer a sus pares extranjeros si es que en el proceso que conocen existen elementos extranacionales. En efecto, tratándose de un proceso derivado del tráfico jurídico internacional o, simplemente, deun 
caso de Derecho internacional privado, la cooperación judicial internacional es fundamental para no ver frustradas las expectativas de la resolución del conflicto de intereses o la eliminación de una incertidumbre por el tribunal competente, ante la necesaria práctica de diligencias fuera del territorio del Estado al que pertenece. En estetrabajo solo nos referiremos al proceso civil con elemento extranjero.

\section{CONCEPTO Y FUNDAMENTO}

La cooperación judicial o asistencia judicial internacional no es más que, el auxilio judicial que se prestan tribunales de distintos Estados para la realización de actos procesales que, por la vigencia del principio de la soberanía, no puede realizar el tribunal del foro fuera de su territorio jurisdiccional, pero sí el tribunal del Estado extranjero en cuyo territorio se deberealizar las notificaciones, medidas cautelares o pruebas que seencarguen y que, tendrán plena validez en el proceso que se sigue por el tribunal del Estado requirente.

De ahí que se conciba a la asistencia judicial internacional "como el auxilio que entre sí se otorgan los órganos jurisdiccionales en y para el desarrollo del proceso" $^{\prime 3}$.

El fundamento deesta importanteinstitución del Derecho internacional privado es, pues, que el desarrollo del proceso civil internacional ${ }^{89}$ prosiga hasta su culminación; sin que la práctica de determinados actos procesales que necesariamente deben realizarse por un órgano jurisdiccional extranjero, no constituya impedimento para lograr el fin del proceso $\mathrm{mismo}^{90}$, el que involucra la realización del ideal dejusticia. De no existir esta institución, sefrustraría el tráfico jurídico internacional.

En estesentido, sedebeseñalar quelos Estados no están obligados a prestar tal ayuda, salvo que estén vinculados a un tratado o convenio sobrela materia que les exige dar cumplimiento a lo acordado ${ }^{6}$; si lo hacen, es en virtud del principio dereciprocidad7. Como lo precisa González Campos, "El auxilio cuando tiene lugar, debe pues ser considerado, salvada la existencia de convenios internacional es que lo impongan, como un acto discrecional del Estado quelo presta, simple manifestación de cortesía internacional del Estado requerido a ell o frenteal Estado requirente, y del interés en obtener, eventual mente, deeste último un tratamiento recíproco" ${ }^{\prime 8}$. 
Cabe señalar que, cierto sector de la doctrina española considera que la base jurídica de la asistencia judicial al no existir tratados que vinculen al Estado requirente y al requerido, es solo la tutela judicial efectiva. Señalan Calvo Caravaca y Carrascosa González, que "...los particulares litigantes tienen derecho a una tutelajudicial efectiva internacional y el Estado, -tanto el Estado requirente como el Estado requerido- tienen el correl ativo deber de prestar a los particulares esa tutela judicial efectiva en los litigios internacionales" ${ }^{9}$. Al respecto, debemos manifestar que no podemos compartir tal tajante posición; en tanto que, el deber u obligación de dar una efectiva tutel a procesal en estricto es solo del Estado del foro, es él quien debesatisfacer las pretensiones delosjusticiables dentro del marco de un proceso justo y en el quesecumplan los "elementos o derechos tradicionalmente considerados como propios de la dimensión procesal del debido proceso" ${ }^{10}$, es él quien tiene que administrar justicia; mi entras queel Estado requerido obra debuena voluntad, porqueasí lo decide ante la petición de la práctica de un acto procesal en su territorio. Consideramos pues, que el Estado extranjero requerido no tiene ninguna obligación o deber de prestar efectiva tutela procesal a los litigantes; en todo caso, coopera con dicha prestación por parte de su par (Estado requirente), proyectándose a que en el futuro pueda recibir similar atención o trato recíproco.

\section{ACTOS PROCESALES QUE REQUIEREN DE ASISTENCIA JUDICIAL INTERNACIONAL}

Tradicional menteseha considerado las notificaciones y la actuación depruebas; a las quesesuma la ejecución demedidas cautelares y, la información y prueba del derecho extranjero ${ }^{11}$.

No cabe duda que el reconocimiento y ejecución de sentencias y laudos arbitrales también requieren dela cooperación judicial internacional; en tanto que las sentencias y laudos solo producen efectos jurídicos en el territorio del Estado quelas emiten y, a fin dequeseextraterritorial icen necesitan ser sometidas al proceso de reconocimiento y ejecución conocido como "exequátur", en el que se ha de tener en cuenta la vigencia de tratados sobre la materia y, a fal ta de ellos, el principio de reciprocidad positiva. Sin embargo, su estudio se realiza de manera independiente de esta institución dada su especial importancia (véase queel LibroX del Código Civil lededica todo un Título, el IV; asimismo es deobservarse lo previsto en la Ley General deA rbitraje); por lo que, en este trabajo obviamos su referencia. 
Marcela Arriola Espino - Cooperación judicial internacional en el sistema de derecho internacional privado peruano

\section{Cartarogatoria}

Es la carta rogatoria o exhorto internacional el mecanismo medianteel cual es viable la cooperación judicial internacional. No es más que la petición que libra una autoridad judicial (en este caso peruana) a su homologo extranjero, con el ruego quellevea cabo una determinada diligencia, práctica de prueba o extienda información del Derecho extranjero necesario para el proceso que tramita.

El exhorto debe tramitarse de acuerdo a las estipulaciones de los convenios o tratados de los que formamos parte y de la ley pertinente. Por lo que debe tenerse en cuenta lo establecido en el artículo $168^{\circ}$ del Texto Único Ordenado de la Ley Orgánica del Poder Judicial: "Cuando se comisione a un juez extranjero para la práctica de una diligencia judicial, se envía exhorto legalizado, utilizando el conducto establecido en el respectivo Tratado, y a falta de éste por el Ministerio de Relaciones Exteriores, invocando la recíproca conveniencia de celeridad procesal. Cuando los exhortos selibren a Cónsules y Agentes Diplomáticos del Perú en el extranjero, se remiten por conducto de Relaciones Exteriores" 12 .

Caberecordar quees la lex fori o ley del tribunal queconoceel litigio, la querige la ordenación del mismo. Tratándose del cumplimiento de actos procesales en el exterior por parte del Estado requerido, debemos preguntarnos quéley es la aplicableal diligenciamiento delos mismos; al respecto, la doctrina y el Derecho comparado coinciden queen estricto no seaplica la lex fori en los supuestos de asistencia judicial internacional, se aplica-entonces- la ley del Estado en donde se ejecuta el acto, con algunas salvedades como la del plazo que se otorga al demandado para que conteste la demanda (emplazamiento), el mismo que sí está sujeto a ley del Estado requirente ${ }^{13}$.

Al respecto, los tratados de los queel Estado peruano forma parteadmiten lo expuesto. El artículo $11^{\circ}$ del Tratado de Derecho Procesal Internacional Montevideo 1889, así como el artículo 391ㅇdel Código Bustamantey el artículo $10^{\circ}$ de la Convención Interamericana sobre exhortos o cartas rogatorias Panamá 1975, advierten queel exhorto internacional sediligencia conformea las leyes del Estado requerido; sin embargo, precisan estos dos últimos tratados que el objeto o fondo de la carta rogatoria debe sujetarse a la ley del Estado comitente o requirente, la Convención Interamericana menciona en su artículo 8b. que los plazos para actuar por parte de la persona notificada y las 
Marcela Arriola Espino - Cooperación judicial internacional en el sistema de derecho internacional privado peruano

advertencias que entrañaría su inactividad están a lo dispuesto por parte del Estado requirente. La Convención Interamericana sobre recepción de pruebas en el extranjero - Panamá 1975, también considera en su artículo $5^{\circ}$ que las cartas rogatorias en que se soliciten recepción u obtención de pruebas se cumplirán de acuerdo con las leyes del Estado requerido, comprendiendo inclusive los medios de apremio que prevén. Mientras que la Convención Interamericana sobre ejecución de medidas preventivas - Montevideo 1979, considera que la ejecución de la medida, la contracautela, variación de la medida y las sanciones por petición maliciosa, se sujetan a la ley del Estado de ejecución; por supuesto, la declaración de procedencia de la medida será conformea las leyes del lugar del proceso o del Estado requirente.

Por otro lado, para librar un exhorto internacional no es necesario que la parte lo solicite; es suficiente que con la petición de real izar determinada diligencia fuera de la circunscripción territorial del tribunal que conoce del proceso (en este caso en el extranjero) y, luego de admitida, el órgano jurisdiccional debe ordenarlo deacuerdo a ley.

Sin embargo, la mal a práctica judicial nos enseña en unos casos, que el Juez espera que el interesado solicite formal mente que aquél pida tal ayuda o auxilio; mientras queen otros, en la resolución que seordena librar exhorto se establece un deber para la parte peticionante, cuál es, de "proporcionar las facilidades del caso". Con ello, el juez no solo no acata el principio de dirección eimpulso procesal contenido en el artículoll del Título Preliminar del Código Procesal Civil, sino que también afecta la tutela jurisdiccional efectiva prevista en el inciso 3 del artículo 139ㅇ de la Constitución Política del Estado.

\section{COOPERACIÓN JUDICIAL INTERNACIONALEN EL ORDENAMIENTO JURÍDICO NACIONAL}

En materia decooperación judicial internacional debemos distinguir el régimen convencional (tratados, convenios, etc.), del régimen común o de producción interna (leyes, decretos, etc.).

Como sabemos, es fuentedel Derecho internacional privado el tratado; Batiffol y Lagardeconsideran quees la fuenteinternacional positiva por excelencia ${ }^{14}$. Gracias a los tratados es posibleacercar a los distintos ordenamientos jurídicos estatales y lograr su armonización, la que a la fecha es parcial y en ciertos 
aspectos o sectores de la referida disciplina; como lo es el Derecho Procesal Civil Internacional y del que forma parte, precisamente, la institución en estudio.

Dado el predominio del tratado sobre la ley, fuente de origen interno, en aplicación extensiva del artículo 20470 del Código Civil, el régimen común de la asistencia judicial internacional se aplica a falta de su regulación mediante acuerdos internacionales. Por ello, Fernández Rozas y Sánchez Lorenzo, consideran que el régimen común tiene carácter residual ante la aplicación prioritaria del régimen convencional ${ }^{15}$.

\section{Régimen Convencional}

En el ámbito del Derecho Internacional Privado, es reconocida la tradición codificadora de A mérica que se inició con la adopción de los Tratados de Montevideo de 1888-1889.

En efecto, La Primera Conferencia de Montevideo cel ebrada de 1888 a 1889 adoptó I os Tratados de Montevideo de 1889; Ia VI Conferencia Internacional Panamericana reunida en La Habana en 1928 aprobó el Código de Derecho Internacional Privado o Código Bustamante; la Segunda Conferencia de Montevideo cel ebrada de 1939 a 1940 adoptó los Tratados de Montevideo de 1940; mientras que en cada una de Ias seis Conferencias Especializadas Interamericanas de Derecho Internacional Privado (conocidas por las siglas de CIDIP), celebradas bajo los auspicios de la Organización de Estados Americanos, se han adoptado diversos instrumentos interamericanos que abarcan diversos temas de la disciplina ${ }^{16}$.

El Perú, está vinculado a los Tratados de Montevideo de 188917, el Código Bustamante de $1928^{18} \mathrm{y}$, las convenciones y protocolo acordado en la Primera y Segunda Conferencia Especializada Interamericana de Derecho Internacional Privado (CIDIP I, cel ebrada en Panamá 1975 y CIDIP II, celebrada en Montevideo 1979) ${ }^{19}$; en consecuencia, estos instrumentos internacionales forman parte del ordenamiento jurídico nacional ${ }^{20}$. Se precisa que el Perú no forma partede los Tratados de M ontevideo 1940.

En materia decooperación judicial internacional en el proceso civil, observamos queel Perú fundamental mentehasuscritoy ratificado acuerdos internacionales multilaterales, y al gunos bilaterales delarga data. 
Marcela Arriola Espino - Cooperación judicial internacional en el sistema de derecho internacional privado peruano

Tratados multilaterales:

- Tratado de Derecho Procesal Internacional . Montevi deo, 1889

El Primer Congreso Internacional Sudamericano de Derecho Internacional Privado, celebrado en Montevideo-Uruguay entre 1888 y 1889, adoptó los Ilamados Tratados de Montevideo de 1889. Uno de ellos, el Tratado deDerecho Procesal Internacional fue suscrito el 11 de enero de 1889 y, ratificado por A rgentina, Bolivia, Paraguay, Perú y Uruguay, seadhirió Col ombia. El Perú lo aprobó medianteResolución Legislativa del 25 deoctubre de 1889, seencuentra vigente desdee 16 de mayo de 1890, fecha desu aceptación.

Este tratado no tiene un Título específico sobre cooperación judicial internacional, pero sí uno -el Título III- subtitulado "Del cumplimiento de los exhortos, sentencias y fallos arbitrales". De manera que, en cuatro artículos, del 9 al 12, seregula sobre los exhortos o cartas rogatorias queson precisamenteel medio por el cual es posible la cooperación judicial y, como ya se ha señalado, es el pedido que una autoridad judicial hace a otra extranjera para que en su territorio practique un determinado acto procesal que es vital para el proceso que conoce.

Es necesario aclarar que la referencia a "exhortos y cartas rogatorias" o a "exhortos o cartas rogatorias", que hacen los artículos $9^{\circ}$ al $12^{\circ}$ e incluso $3^{\circ}$ de este tratado, debe entenderse que es a un mismo término: el exhorto internacional.

0 bjeto de los exhor tos 0 cartas rogatorias. Conforme al artículo 9o del tratado, lo será "hacer notificaciones, recibir declaraciones o practicar cualquiera otra diligencia de carácter judicial". Este contenido es bastante amplio; pues, comprende los clásicos actos procesales que requieren de asistencia judicial, como lo son realizar notificaciones, actuación de pruebas en general, ejecución demedidas cautelares, $y$, nos permitimos considerar informar sobreel Derecho extranjero. Precisamente, el artículo $10^{\circ}$ del tratado complementa el artículo anterior al considerar quelos exhortos pueden referirsea embargos, tasaciones, inventarios o diligencias preventivas.

R equisito del exhorto o carta rogatoria. Es condición establecida por el artículo 9o en concordancia con losartícul os 3y $4^{\circ}$ del tratado, queel exhorto librado esté debidamentelegalizado por la vía diplomática. 
Ley aplicableal diligenciamiento del exhorto. Lo será la ley del Estado en donde se pida la ejecución de una diligencia; según lo establece el artículo 11o del tratado. Claro está que esta prescripción está referida a la ley aplicable a la forma que debeobservarse para la actuación o el diligenciami ento del exhorto internacional.

A poderados y gastos. La parteinteresada en la ejecución del exhorto internacional, podrá nombrar apoderados en el Estado requerido; debiendo asumir los gastos que estos apoderados y las diligencias ocasionen. Así se advierte del artículo $12^{\circ}$ del tratado.

- Código deD erecho I nternacional Privado o Código Bustamante. La Habana, 1928

En la Sexta Conferencia Panamericana celebrada en La Habana - Cuba en 1928, seadoptó el Código de Derecho I nternacional Privado el 20 defebrero de 1928, quepor acuerdo dela misma Conferencialleva por título oficial el nombre de "Código Bustamante". La Convención y el Código contenido en la misma, fue aprobada y ratificada por el Perú sin reservas mediante Resolución Legislativa $\mathrm{N}^{\circ} 6442$ de 31 de diciembre de 1928 y, promulgada el 8 de enero de 1929, se depositó el instrumento de ratificación el 19 de agosto de 1929.

Los Estados ratificantes de este Tratado son: Bolivia, Brasil, Costa Rica, Cuba, Chile, Ecuador, El Salvador, Guatemala, Haití, H onduras, N icaragua, Panamá, Perú, República Dominicana, y Venezuela. Formularon reservas: Bolivia, Brasil, Costa Rica, Chile, Ecuador, El Salvador, Haití, República Dominicana y Venezuela.

El Código Bustamante tieneun Título Preliminar y cuatro Libros. Su Libro IV sobre Derecho Procesal Internacional, contempla en su Título Quinto regulación sobre los exhortos o cartas rogatorias.

Competencia. Establece el artículo 3899 de este tratado que corresponde al juez exhortanteo tribunal del foro decidir sobresu competencia, así como la legalidad y oportunidad del acto procesal a diligenciarse. Por su parte, según el artículo $390^{\circ}$ de la misma norma, el Juez exhortado determinará su competencia en razón de la materia para actuar el acto procesal que se le encarga.

0 bjeto de los exhortos o cartas rogatorias. Conforme al artículo 3880 del Código Bustamante, lo será toda diligencia judicial queun Estado contratantenecesite 
practicar en otro. Estanorma permiteconsiderar cualquier acto procesal (llámese notificaciones, pruebas, medidas cautelares, etc.) que requiera el tribunal del Estado requiriente, para dar una efectiva tutela procesal y que, solo podría ejecutarse por el tribunal extranjero requerido.

R equisito del exhorto o carta rogatoria. Es requisito establecido en el artículo 388 del Código Bustamante, que el exhorto sea cursado por la vía diplomática. A demás, debeser redactado en el idioma del Estado exhortante, acompañado con una traducción en el idioma del Estado exhortado, hecha por traductor oficial o, como lo indica el artículo 3920 del tratado, por intérpretejuramentado.

Ley aplicableal diligenciamiento del exhorto. Claramenteseñala el artículo 391ㅇe de esteinstrumento internacional, quela ley aplicablea la forma dela actuación o cumplimiento del exhorto o carta rogatoria, será la del Estado requerido. A demás, estableceque en cuanto al objeto del mismo setendrá en cuentala ley del Estado requirente.

A poderados y gastos. A diferenciadel artículo $12^{\circ}$ del Tratado de Derecho Procesal Internacional - Montevideo 1889, que establece una facultad a favor de la parte interesada denombrar apoderado en el Estado requerido para actuar el contenido de la carta rogatoria; el artículo 3930 del Código Bustamante establece una obligación al respecto, debiendo la parte interesada asumir los gastos en que incurran los apoderados nombrados, así como los gastos que ocasionen las diligencias.

- Convención Interamericana sobre Exhortos o Cartas Rogatorias. Panamá, 1975

Fue adoptada en la Primera Conferencia Especializada Interamericana sobre Derecho Internacional Privado (CIDIP I), convocada por la Organización de Estados A mericanos, celebrada en la ciudad de Panamá - Panamá en 1975; a la fecha, forman parte de ella diecisiete Estados ratificantes: Argentina, Bolivia, Brasil, Colombia, Costa Rica, Chile, Ecuador, El Salvador, Estados Unidos, Guatemala, Honduras, México, Panamá, Paraguay, Perú, Uruguay, Venezuela y, un Estado adherente: España.

No cabe duda que inspirada en la labor codificadora de la Conferencia de La Haya ${ }^{21}$ la CIDIP I inició la tarea de la codificación en el sector del Derecho 
Procesal Internacional, con la adopción de dos importantes convenciones; una de ellas, es ésta sobre cartas rogatorias quela misma convención seencargó de establecer que tal referencia y la de exhortos se utilizan como sinónimos en el idioma español y, la otra, es sobrela recepción de pruebas en el extranjero, que veremosseguidamente.

\section{Alcance de la Convención:}

Conformeal artículo $2^{\circ}$ dela Convención, seaplica al os exhortos internacionales ordenados en procesos civiles y comerciales y, que tengan por objeto: a) La realización deactos procesal es demero trámite, como notificaciones en general, la que puede comprender citaciones o emplazamientos; y, b) La recepción y obtención de pruebas, einformes en el extranjero. La Convención, no seaplica a actos que impliquen ejecución coactiva. Cabe precisar que un Estado parte podrá negarsea dar cumplimiento a un exhorto, si es manifiestamentecontrario al orden público establecido en el mismo.

Transmisión del exhorto internacional

El artículo 4이 de la Convención permite que los exhortos sean trasmitidos o transferidos no solo por la clásica vía judicial o, por los funcionarios consulares o agentes diplomáticos, sino también por las propias partes interesadas o por la autoridad central del Estado requirente o requerido según el caso.

Requisitos:

Son dos los requisitos quese deben cubrir para diligenciar los exhortos o cartas rogatorias: 1) Que estén legalizados, salvo dos excepciones: a) Que su transmisión se realicepor vía consular, vía diplomática, o por intermedio dela autoridad central y, b) Queel tribunal requerido estéubicado en zonafronteriza de los Estados parte; y, 2) Que estén traducidos al idioma oficial del Estado requerido; así como también, la documentación que se anexa, la misma que indefectiblemente debe comprender copia autenticada de la demanda y sus anexos, así como de los escritos o resoluciones que sirvan de fundamento a la diligencia solicitada e, información sobre cuál es el órgano jurisdiccional requirente, los térmi nos previstos para que la persona notificada actúe y, las advertencias de dicho órgano sobre las consecuencias que entrañaría su inactividad. 
Tramitación del exhorto internacional:

Se hará conforme a las normas procesales del Estado requerido, como así lo señala el artículo diez dela Convención; sin embargo, tratándose del fondo de lo que es materia de di ligenciamiento, como plazos para actuar por partedela persona notificada o apercibimiento a ejecutarse en caso de no acatar lo dispuesto por el Estado requirente, se tendrá en cuenta lo previsto por éste; como además se advierte del artículo 8b. de esta norma. Según lo establece el artículo 11으 de la Convención y, como es lógico, el Estado requerido tendrá competencia para conocer de las cuestiones o incidencias que se susciten con motivo del cumplimiento de la diligencia solicitada.

Actuación de los funcionarios consulares o agentes diplomáticos:

Queda limitada a la autorización expresa o tácita del Estado parte a través de sus leyes internas; es decir, si las normas del Estado receptor del funcionario no se oponen a su actuación para dar cumplimiento a los exhortos, actuarán; en caso de poder actuar, no podrán ejercer coerción de ninguna clase. Lo que concuerda con el artículo 524으 del Reglamento Consular del Perú.

Costas y otros gastos:

Son asumidas por los interesados; sin embargo, conforme al artículo 120 de la Convención, se podrá otorgar el beneficio de pobreza o auxilio judicial, como se denomina en el Perú, de acuerdo a las leyes del Estado requerido.

- Convención Interamericana sobre Recepción dePruebas en el Extranjero. Panamá, 1975

A doptada en la Primera Conferencia Especializada Interamericana sobre Derecho Internacional Privado, convocada por la Organización de Estados A mericanos, celebrada en la ciudad dePanamá - Panamá en 1975; a la fecha la han ratificado quince Estados americanos: Argentina, Colombia, Costa Rica, Chile, Ecuador, El Salvador, Guatemala, Honduras, México, Panamá, Paraguay, Perú, República Dominicana, Uruguay y Venezuela.

EstaConvención complementa a la Convención Interamericana sobreExhortos o Cartas Rogatorias, pues ésta ya prevéla actuación depruebas en el extranjero 
previa libración de exhortos; lo que hace la Convención sobre Pruebas en el Extranjero es establecer ciertas precisiones que indicaremos.

Por otro lado, del listado de Estados parte de las Convenciones referidas, podemos advertir Estados vinculados a ambos instrumentos, Estados quesolo participan dela Convención sobreExhortoso Cartas Rogatoriasy, Estadosque solo son parte de esta Convención. Así, Bolivia, Estados Unidos y España vinculados a la Convención sobre exhortos o cartas rogatorias, no participan de la Convención sobre Recepción de Pruebas en el Extranjero; mi entras que República dePanamá, Estado partedeesta Convención no participa deaquélla.

\section{Alcance de la Convención:}

De acuerdo al artículo 2o de la Convención, se diligenciarán exhortos provenientes de procesos judiciales en materia civil y comercial, quetengan por objeto la actuación de todo tipo de pruebas e informes, siempre que no sean contrarias a las leyes del Estado requerido que expresamentela prohíban, y el interesado proporcioneal servicio del órgano jurisdiccional requerido los medios necesarios para el diligenciami ento de la prueba solicitada. A demás, se debe tener en cuenta que el Estado requerido podrá negarse a dar cumplimiento al exhorto librado cuando sea manifiestamente contrario a su orden público.

Transmisión del exhorto internacional:

Los exhortos queselibren para la actuación de pruebas, según esta Convención, sehan detransmitir al órgano requerido por víajudicial, por intermedio delos funcionarios diplomáticos o consulares o por la autoridad central del Estado requirente o requerido, según el caso. No seprevéque los propios interesados transmitan el exhorto al órgano requerido, como sí lo hacela Convención sobre Exhortos o Cartas Rogatorias; sólo se utiliza la vía oficial que implicaría seguridad en el trámitey celeridad.

Requisitos:

Los establece el artículo $10^{\circ}$ de la Convención. Los exhortos deben estar legalizados, salvo que sean transmitidos o devueltos por vía consular o diplomática, o a través dela autoridad central; no seexceptúa la actuación por tribunales fronterizos como lo hace la Convención sobre Exhortos o Cartas Rogatorias. Asimismo, deben estar traducidos al idioma oficial del Estado requerido, como también la documentación anexa. 
Tramitación:

Losexhortos sobreactuación depruebas en el extranjero, secumplirán deacuerdo a las leyes procesales del Estado requerido; comprendiendo la utilización delos medios de apremio previstos en ellas. La Convención prevé que, el órgano jurisdiccional requerido está facultado para conocer de las cuestiones que se susciten a propósito del cumplimiento de la diligencia (tachas, oposiciones). Tratándose de personas Ilamadas a declarar, podrán negarse a ello por impedimento, excepción o deber derehusar su testimonio, según la ley del Estado requerido o del Estado requirente; si seinvocalaley deesteúltimo, el impedimento, excepción o deber de rehusar testimoniar debe estar previsto en el exhorto o, confirmarsepor la autoridad requirentea petición del tribunal requerido.

- Convención Interamericana sobre Ejecución de Medidas Preventivas. M ontevideo, 1979

Acuerdo internacional adoptado en la Segunda Conferencia Especializada Interamericana sobre Derecho Internacional Privado, convocada por la Organización de Estados A mericanos, cel ebrada en la ciudad de M ontevideo República Oriental del U ruguay en 1979; son Estados ratificantes: Argentina, Colombia, Ecuador, Guatemala, Paraguay, Perú y Uruguay.

Esta Convención cubreel vacío dela Convención Interamericana sobreExhortos o cartas Rogatorias aprobada en la CIDIP I, al no comprender actos procesales queimpliquen ejecución coactiva.

El artículo $1^{\circ}$ de la Convención precisa que "las expresiones "medidas cautelares", "medidas de seguridad" o "medidas de garantía" se consideran equivalentes cuando se utilizan para indicar todo procedimiento o medio que tienda a garantizar las resultas o efectos deun proceso actual o futuro en cuanto a la seguridad de las personas, de los bienes o delas obligaciones de dar, hacer o no hacer una cosa específica, en procesos denatural eza civil, comercial, laboral y procesos penales en cuanto a la reparación civil".

Alcance de la Convención:

Se establece que los jueces o tribunales de los Estados Partes podrán ejecutar medidas cautelares que tengan por objeto: a) El cumplimiento de medidas necesarias para garantizar la seguridad de las personas, como custodia de 
hijos menores o alimentos provisionales $\mathrm{y}, \mathrm{b}$ ) El cumplimiento de medidas necesarias para garantizar la seguridad de los bienes, tales como embargos, secuestros preventivos debienes inmuebles y muebles, inscripción de demanda o administración eintervención de empresas.

Ley aplicable:

Debe tenerse en cuenta quela ley aplicable a la declaración de procedencia de la medida cautelar, es la del lugar del proceso; mientras quela ley aplicablea la ejecución de la medida cautelar, a la contracautela y garantía, así como a la modificación o variación de la mediday, las sanciones por petición maliciosa o abusiva, es la del lugar dondesesolicita su cumplimiento. Ello en concordancia con los artícul os 3y 4ํ de la Convención.

Tramitación:

Medianteexhorto sesolicitará el cumplimiento de una medida cautelar y serán transmitidos al órgano requerido por las propias partes interesadas, por vía judicial, por vía consular o diplomática o por la autoridad central del Estado requirenteo requerido, según el caso. Los exhortoso cartas rogatorias requieren legal ización y, traducción al idioma oficial del Estado requerido, así como dela documentación que se anexe. En cuanto a la ley aplicableya se ha señalado en acápite anterior.

\section{Tercería:}

El artículo 5o de la Convención establece que se podrá formular tercería u oposición pertinente, con el único objeto de que sea comunicada al juez de origen al devolvérseleel exhorto. Informado el juez requirente, suspenderá el trámite del proceso principal por un término no mayor a sesenta días con el objeto de que el afectado haga valer sus derechos. Si la tercería interpuesta es excluyentededominio, o laoposición sefundamentareen la posesión o dominio del bien embargado, es competentee juez del lugar desituación del bien afectado y resolverá aplicando su ley.

Costas y gastos:

En el trámite y ejecución de las medidas cautelares, las costas y demás gastos son asumidas por los interesados. Según el artículo 16dela Convención, queda 
a criterio del Estado requerido dar trámiteal exhorto quecarezca de indicación de la parte que ha de cubrirlos, salvo que se trate de alimentos provisionales; pues, solo en este caso se diligenciará de oficio.

- Convención I nteramericana sobrePruebase Información acerca del Derecho Extranjero. M ontevideo, 1979

Fue adoptada en la Segunda Conferencia Especial izada Interamericana sobre Derecho Internacional Privado, convocada por la Organización de Estados Americanos, celebrada en la ciudad de Montevideo - República Oriental del Uruguay en 1979. Son Estados parte: Argentina, Brasil, Chile, Colombia, Ecuador, Guatemala, M éxico, Paraguay, Perú, Uruguay, Venezuela, quela han ratificado y, España, adherida a ella.

En la CIDIP I se reguló lo relacionado a la recepción y obtención de prueba sobre hechos, más no del derecho extranjero; lo que se subsanó con la labor de Ia CIDIP II, al adoptar esta Convención ${ }^{22}$.

La Convención establece que los Estados parte pueden obtener elementos de prueba einformación del derecho de cada uno deellos; sin embargo, el Estado requerido no estaráobligado a responder a la consultaformuladasi susintereses estuvieren afectados por la cuestión que dio origen a la información, o cuando la respuesta pudiere afectar su seguridad o soberanía.

\section{Alcances de la Convención:}

Proporcionar a las autoridades de los Estados parte las pruebas o informes sobreel texto, vigencia, sentido y al cancelegal del derecho del Estado requerido; conforme a su artículo 2 ㅇ.

Medios deprueba:

Según el artículo 3o de este tratado, la cooperación que se prestará se hará a través de los medios de prueba previstostanto por la ley del Estado requirente como por la del Estado requerido. Sin embargo, son medios de prueba idóneos para esta Convención: a) La prueba documental, consistente en copias certificadas de textos legales con indicación de su vigencia, o de precedentes judiciales; b) La prueba pericial, consistente en dictámenes de abogados o expertos en la materia; c) Los informes del Estado requerido sobre el texto, vigencia, sentidoy alcancelegal de su derecho sobre determinados aspectos. 
Informes sobre Derecho extranjero:

La cooperación en estesentido no se limita a autoridades judiciales; los Estados parte discrecionalmente podrán atender las solicitudes de informes de otras autoridades, como administrativas por ejemplo, según seadvierte del artículo 4ํdela Convención. La información solicitada y proporcionada sobre Derecho extranjero, no obliga al Estado requirenteaplicar el derecho según el contenido dela respuesta, ni al Estado requerido a exigir seaplique su derecho conforme a la respuesta dada; así lo estableceel artículo 60 de la Convención.

Transmisión de la solicitud:

El artículo 70 de la Convención ha previsto que la autoridad jurisdiccional solicitante pueda dirigirse directamente a la autoridad central del Estado requerido, o también puedehacerlo a través desu autoridad central.

- Protocolo adicional ala Convención Interamericana sobre Exhortoso Cartas Rogatorias. Montevideo, 1979

Instrumento adoptado en la Segunda Conferencia Especializada Interamericana sobreDerecho Internacional Privado, convocada por la Organización deEstados A mericanos, celebradaen la ciudad M ontevideo-República Oriental del Uruguay en 1979; forman parte de él como Estados ratificantes: Argentina, Brasil, Colombia, Ecuador, El Salvador, Estados Unidos, Guatemala, México, Panamá, Paraguay, Perú, Uruguay y Venezuela, y como Estado adherente: Chile.

\section{Alcancedel Protocolo:}

El Protocolo crea documentos (formularios) y establece reglas deactuación de la autoridad central del Estado requirentey del Estado requerido, intervinientes en el trámitede exhortos cuyo objeto solo sea dar cumplimiento a las actuaciones previstas en el artículo 20 de la Convención Interamericana sobre Exhortos o Cartas Rogatorias.

Elaboración de los exhortos o cartas rogatorias:

Los exhortos deben elaborarse conforme al formulario " $\mathrm{A}$ " del anexo de este Protocolo; el formulario " $\mathrm{B}$ " contendrá información esencial para la persona o autoridad a quien deban ser entregados los documentos; mientras que en el 
formulario " $\mathrm{C}$ ", la autoridad central del Estado requerido deberá certificar si se cumplió o no el exhorto.

Transmisión y diligenciamiento del exhorto:

Deacuerdo con el artículo 4이 Protocolo, recibido el exhorto por la autoridad central del Estado requerido, éste lo transmitirá al órgano jurisdiccional competente para su diligenciamiento conforme a la ley interna competente. Cumplido con lo dispuesto por el exhorto librado, la autoridad judicial que lo haya diligenciado dejará constancia del cumplimiento y lo remitirá a su autoridad central con los documentos pertinentes; mientras queésta certificará la ejecución realizada y, enviará toda la documentación al Estado requirente.

\section{Costas y gastos:}

Seestablece queel diligenciamiento de cartas rogatorias por autoridad central y losórganos jurisdiccional es del Estado parterequerido es gratuito. N o obstante, esteEstado podrá reclamar el pago delas actuaciones que, según su ley interna, deban ser sufragadas directamente por los interesados; como así lo señala el artículo $5^{\circ}$ de esteinstrumento.

\section{Tratados bilateral es}

Cabemencionar los tratados bilateral es queel Perú tiene con Brasil, A rgentina y Chile, sobreexhortos o cartas rogatorias: Convenio sobre recíproca ejecución de cartas rogatorias suscrito con Brasil el 29 de setiembre de 1879, aprobado por Resolución Legislativa del 24 deoctubrede1879; Acuerdo sobreexhortoso cartas rogatorias de la Región A mazónica con Brasil, suscrito el 8 de junio de 1891, aprobado por Resolución Legislativa de25 deoctubre de 1892, promulgado el 4denoviembre de 1892, entró en vigor el 27 demayo de 1893; Convenio sobre Exhortos Judiciales con la República A rgentina, firmado el 2 de julio de 1935, aprobado por Decreto Ley N¹4572 de 19 de julio de 1963, entró en vigor el 26 dejulio de 1963; Convenio sobre Exhortos J udiciales con la República de Chile, firmado el 5 de julio de 1935, aprobado por Resolución Legislativa ${ }^{\circ}{ }^{\circ} 10185$ de 18deenero de 1945, promul gado el 2 defebrero de 1945, entró en vigencia el 17 de abril de $1945^{23}$.

El Convenio que el Perú tiene suscrito con Brasil de fecha 29 de setiembre de 1879, se refiere a la ejecución de cartas rogatorias provenientes de procesos penales y 
civiles. Concretamente en materia civil, pueden tener por objeto citaciones, interrogatorios, declaración detestigos, procuración, examen, copias, verificación, remisión dedocumentos y cualquier otra diligencia conducentea la decisión de la causa, siempre que fueran permitidas por la legislación de los dos Estados contratantes; conformesetienedelosartículos Il y III del referido instrumento.

El A cuerdo sobre exhortos o cartas rogatorias de la R egión A mazónica, suscrito con Brasil el 8 de junio de 1891, tiene por objeto ampliar el acuerdo suscrito el 29 de setiembre de 1879, a fin de facilitar los exhortos de citación o emplazamiento que deban ejecutarseen el Departamento de Loreto o en losEstados del Paráo Amazonas. Se establece que estos exhortos se legal izarán en los Consulados respectivos $y$, se transmitirán a los jueces por el prefecto peruano y por los gobernadores de los referidos Estados.

El Convenio sobre Exhortos Judiciales con la República A rgentina, firmado el 02 de julio de 1935, es de contenido amplio. Ello significa quees posiblela práctica de cualquier actuación judicial en las "respectivas jurisdicciones" de los Estados parte, a través del mecanismo del exhorto, el queno requiere delegalización de las firmas correspondientes si es que es cursado por la vía diplomática. De su artículo I se advierte asimismo, que la ley aplicable al diligenciamiento del exhorto es la del Estado requerido.

El Convenio sobre Exhortos Judiciales con la República de Chile, suscrito el 5 de julio de 1935, también es decontenido amplio; en tanto quede su texto no seadvierte cuál debe ser el objeto del exhorto librado, ni el tipo de proceso del que debe proceder. En consecuencia, los exhortos que uno de los Estados parte libre a otro, pueden estar referidos a notificaciones en general, pruebas, informes del Derecho, etc. y, proceder de proceso civil, comercial, etc. El artículo I de este tratado solo indica que los exhortos para su recepción y diligenciamiento no necesitan estar legalizados, siempre que sean cursados por la vía diplomática con nota oficial.

Es preciso señalar queel 28 demarzo del 2007, el Perú y Colombia suscribieron el Tratado sobre Cooperación Judicial en materia civil, comercial y administrativa; aun no está ratificado. El tratado prevéla cooperación judicial respecto a notificaciones, práctica y obtención de pruebas, intercambio de información sobre legislación y jurisprudencia, e incluso en el sector de reconocimiento y ejecución de sentencias y laudos arbitrales que, de ordinario ha merecido un tratamiento particular. 
Marcela Arriola Espino - Cooperación judicial internacional en el sistema de derecho internacional privado peruano

\section{Régimen Común}

Trata dela regulación de la cooperación judicial internacional a falta denorma convencional o tratado; setieneen cuenta entonces, el principio dereciprocidad.

Seha de librar carta rogatoria a través del Ministerio de Relaciones Exteriores para queel acto procesal sea realizado por la autoridad extranjera requerida, 0 por el funcionario consular del Estado requirente en la correspondiente circunscripción, no importando la nacionalidad del destinatario (puede ser peruano o extranjero) y, si emprequetal práctica no se oponga a la legislación del Estado requerido.

Así seadviertedel artículo 168이 Texto Único Ordenado dela Ley Orgánica del Poder Judicial. A falta de tratado, si el exhorto está dirigido a autoridad judicial extranjera, debe estar legalizado y se transmitirá vía Ministerio de Relaciones Exteriores "invocando la recíproca conveniencia de celeridad procesal". Igual conducto se utiliza si los exhortos se libran a funcionarios consulares peruanos, por parte de los jueces nacionales, para efectuar notificaciones y actuar todo tipo de pruebas, sin la posibilidad de utilizar apremios, conformealo previsto por el artícul 0 524이 Reglamento Consular, Decreto Supremo N ${ }^{\circ}$ 076-2005-RE.

Final mente, es importantetener en cuentaqueel ejercicio defunciones judiciales o de ejecución extraterritorial de los actos del proceso civil, les compete a los Cónsules de manera directa en base a lo previsto por el derecho consular consuetudinario, el derecho convencional multilateral y bilateral, y el derecho interno delosEstados ${ }^{24}$. Por ello, se debeobservar el artículo 5j) dela Convención de Viena sobre Relaciones Consulares, del 24 de abril de 1963, que establece que es función consular "comunicar decisiones judiciales y extrajudiciales y diligenciar comisiones rogatorias de conformidad con los acuerdos internacionales en vigor $\mathrm{y}$, a falta de los mismos, demanera que sea compatible con las leyes y reglamentos del estado receptor"; asimismo, los artículos $524^{\circ}$ a 534ㅇdel Decreto Supremo N 076-2005-RE, Reglamento Consular del Perú, que regula las funciones judiciales de los cónsules peruanos.

\section{CONCLUSIÓN}

La voluntad de los Estados en colaborar con la efectiva administración dejusticia en los procesos civiles con el emento extranjero, hace posiblequese practiquen 
Marcela Arriola Espino - Cooperación judicial internacional en el sistema de derecho internacional privado peruano

actos procesales fuera dela circunscripción del tribunal deorigen del proceso. Tal voluntad manifestada en forma expresa, con la adopción de tratados, o en forma tácita, cada vez que al Estado requerido se le solicita practicar una diligencia y la hace, muchas veces en espera de reciproca actitud, permite considerar quela institución decooperación judicial internacional no esilusoria, sino más bien real, lográndoseflexibilizar el concepto desoberanía y el principio deterritorialidad del proceso.

Como se ha visto, el Perú forma parte de importantes convenciones sobre la materia que involucran a un significativo número de Estados americanos; mientras que la concertación bilateral es mínima y data de hace muchos años. Sin embargo, la falta de cel ebración de tratados con otros Estados, no es óbice para que la cooperación judicial internacional se de y sea efectiva, a la luz del régimen común que prevé el ordenamiento jurídico nacional teniendo como base el principio de reciprocidad.

1 Loewenstein, K.. Teoría dela Constitución. 2ạ. ed., Barcelona: A riel, 1970, p. 55.

2 Couture, E.J. Fundamentos del Derecho Procesal Civil. 4ạ. ed., M ontevideo-Buenos Aires: B deF Ltda., 2005, p.25.

3 Miralles Sangro, P.P. En: Derecho Internacional Privado. Vol. I, 5ạ. ed., 2a. reimpresión, M adrid: Colex, 2006, p.480.

4 Proceso civil internacional es sinónimo de proceso derivado del tráfico jurídico internacional o proceso civil con el emento extranjero. Caberecordar que el el emento extranjero puedeestar referido a la persona, al bien o al acto celebrado por las partes.

5 El artículo III del Título Preliminar del Código Procesal Civil, señala en su primer párrafo: “El Juez deberá atender a quela finalidad concreta del proceso es resolver un conflicto deintereses o elimi nar una incertidumbre, ambas con rel evancia jurídica, haciendo efectivos los derechos sustanciales, y que su finalidad abstracta es lograr la paz social en justicia".

6 Convención de Viena sobre el Derecho de los Tratados, de la que el Perú forma parte: "Artículo 26. "Pacta sunt servanda".- Todo tratado en vigor obliga a las partes y debe ser cumplido por ellas de buena fe".

7 En cuanto al principio de reciprocidad: “...actitud que un Estado adopta por propia voluntad a falta de norma expresa -en este caso un tratado- en respuesta simétrica o similar a la ya adoptada por otro Estado". Arriola Espino, Marcela T. En: Código Civil Comentado por los 100 mejores especialistas. Lima: Gaceta Jurídica, 2005, p.894.

8 González Campos, J.D. Derecho Internacional Privado. Parte Especial. Vol. I, Oviedo: Gofer, 1984, p357. Vid. además, Fernández Rozas, J.C. y Sánchez Lorenzo, S. Derecho Internacional Privado. 3ª ed., Madrid: ThompsonCivitas, 2004, p.260-261.

9 Calvo Caravaca, A. L. y Carrascosa González, J. Derecho Internacional Privado. Vol . I, 7ạa ed., Granada:Comares, 2006, p.417.

10 Espinosa-Saldaña Barreda, E. Jurisdicción Constitucional, Impartición de Justicia y Debido Proceso. Ed. ARA, Lima, ps.420. Vid. Artículo 139 de la Constitución Política del Estado.

11 Calvo Caravaca, A . L. y Carrascosa Gonzáles, J. Op. cit, p.611. Rouvier, J.M. Problemas de Derecho Procesal Internacional en América Latina: Convenciones de la CIDIP-I y Proyectos de la CIDIP-II. Referencia Especial a la Legislación Venezolana. En: OEA-Comité Jurídico Interamericano. Cursos de Derecho Internacional . 
Marcela Arriola Espino - Cooperación judicial internacional en el sistema de derecho internacional privado peruano

SerieTemática Vol. I (Partel): El Derecho Internacional Privado en las A méricas (1974-2000), Wahington D.C., 2002, p.170.

12 Vid. además artícul os 150 y 151 del Código Procesal Civil y, artículos 524a 534 del Reglamento Consular del Perú: Decreto Supremo N076-2005-RE.

13 Vid. Grieder Machado, H. En: Lecciones deDerecho Procesal Civil Internacional. A guilar Benitez de Lugo, M. y otros. Sevilla: Universidad deSevilla, 2002, p.123-124. García Calderón, M. Derecho Internacional Privado. Lima: UN MS, 1969, p.366. Lazcano, Carlos A. Derecho Internacional Privado. Buenos Aires: Platense, 1965, p.642-644.

14 Batiffol, H. y Lagarde, P. Droit International Privé. T.I., 6a. ed., Paris: Librairie genérale de droit et de jurisprudence, 1974, p..31.

15 Fernández Rozas, J C. y Sánchez Lorenzo, S. Op. cit. p.261.

16 Vid. Alfonsin, Q. Teoría del Derecho Privado Internacional. M ontevideo: Idea, 1982, p.278-88. www.oas.org

17 Ellos son: Tratado de Derecho Procesal Internacional, Tratado de Propiedad Literaria y Artística, Tratado sobre Patente de Invención, Tratado de Marcas de Comercio y de Fábrica, Tratado de Derecho Penal Internacional, Tratado sobre Ejercicio de Profesiones Liberales, Tratado sobre Derecho Civil Internacional, Tratado de Derecho Comercial Internacional, Protocolo Adicional sobre A plicación de las Leyes Extranjeras.

18 Comprende un Título Preliminar y cuatro Libros: de Derecho Civil Internacional, de Derecho Mercantil Internacional, deDerecho Penal Internacional y de Derecho Procesal Internacional.

19 En la CIDIP I, Panamá 1975, se adoptaron seis convenciones: Convención Interamericana relativa a conflicto deleyes en materia deletras de cambio, pagarés y facturas; Convención Interamericana relativa a conflicto de leyes en materia decheques; Convención Interamericana sobre arbitrajecomercial internacional; Convención Interamericana sobre exhortos o cartas rogatorias; Convención Interamericana sobre recepción de pruebas en el extranjero; y, Convención Interamericana sobrerégimen legal depoderes para ser utilizados en el extranjero. En Ia CIDIP II, M ontevideo 1979, se adoptaron los siguientes instrumentos internacionales: Convención Interamericana sobre conflicto deleyes en materia de cheques; Convención Interamericana sobreconflicto de leyes en materia de sociedades mercantiles; Convención Interamericana sobre eficacia extraterritorial delas sentencias y laudos arbitrales extranjeros; Convención Interamericana sobre cumplimiento de medidas cautelares; Convención Interamericana sobre prueba einformación acerca del derecho extranjero; Convención Interamericana sobre domicilio de las personas físicas en el Derecho Internacional Privado; Convención Interamericana sobre normas generales del Derecho Internacional Privado; y, Protocolo Adicional a la Convención Interamericana sobre exhortos o cartas rogatorias.

20 Vid. Artículo 55 dela Constitución Política del Estado; A rtículo 24 dela Convención de Viena sobreel Derecho de los Tratados.

${ }^{21}$ Fuentedel nspiración lo fueron los Convenios de La Haya de de 1 de marzo de 1954 sobreprocedimiento civil, del 15 de noviembre de 1965 relativo a la notificación o traslado en el extranjero delos documentos judiciales o extrajudiciales en materia civil o comercial y, el de 18 de marzo de 1970 sobre obtención de pruebas en el extranjero en materia civil o mercantil.

22 De Maekelt, T. B. Resultados de la Segunda Conferencia Especializada Interamericana sobre Derecho Internacional Privado (CIDIP-II). En: Organización delos Estados A mericanos-Comitéj urídico Interamericano. Cursos de Derecho Internacional. Serie Temática, Vol. I (Partel): El Derecho Internacional Privado en las A méricas (1974-2000), Washington D.C., 2002, p.310.

23 Fuente: Dirección de Tratados del Ministerio de Relaciones Exteriores y, Dirección de Coordinación con la Administración de Justicia del Ministerio de Justicia.

${ }^{24}$ Maresca, A. Las relaciones consulares. Madrid: A guilar, 1974, p.330. 